\title{
Artificial Intelligence: The New Alexander Fleming
}

\author{
Zaki Almallah ${ }^{1}$, Rania El-Lababidi ${ }^{2}$, Farah Shamout ${ }^{3}$, Daniel John Doyle ${ }^{4}$ \\ 'Department of Urology, Cleveland Clinic Abu Dhabi, Abu Dhabi, UAE \\ ${ }^{2}$ Antimicrobial Stewardship Program, Cleveland Clinic Abu Dhabi, Abu Dhabi, UAE \\ ${ }^{3}$ Department of Computer Engineering, New York University, Abu Dhabi, UAE \\ ${ }^{4}$ Department of General Anesthesiology, Cleveland Clinic Abu Dhabi, Abu Dhabi, UAE
}

Almost a century after Alexander Fleming discovered penicillin and forever changed the face of medicine, Massachusetts Institute of Technology (MIT) researchers made another discovery potentially as valuable as Fleming's ground-breaking work. They used artificial intelligence (AI) algorithms based on machine learning to trawl through a vast digital collection of pharmaceutical compounds to identify novel antibacterial molecules [1], and identified a new antibiotic that they dubbed halicin (named after 2001's HAL 9000). Halicin, it turns out, acts in a manner different from conventional antimicrobials - by damaging the ability of bacteria to maintain an electrochemical gradient necessary for survival.

In the MIT study, a deep neural network model was developed to screen millions of molecules in mere days to identify potential antibiotics that employ mechanisms different from those of existing drugs. After screening numerous chemical libraries, the team identified halicin from the Drug Repurposing Hub [2], as a compound that shows bactericidal action against a wide assortment of pathogens, including

Submitted: September 26, 2020

Revised: January 3, 2021

Accepted: February 24, 2021

\section{Corresponding Author}

Zaki Almallah

Department of Urology, Cleveland Clinic Abu Dhabi, Al Maryah Island, Abu Dhabi 112412, UAE. Tel: +97125019999, E-mail: almally@ clevelandclinicabudhabi.ae (https://orcid.org/0000-0003-0746-7001)

This is an Open Access article distributed under the terms of the Creative Commons Attribution Non-Commercial License (http://creativecommons.org/licenses/by$\mathrm{nc} / 4.0 /$ ) which permits unrestricted non-commercial use, distribution, and reproduction in any medium, provided the original work is properly cited.

(C) 2021 The Korean Society of Medical Informatics
Mycobacterium tuberculosis, carbapenem-resistant Enterobacteriaceae, Clostridioides difficile, and Acinetobacter baumannii. This seminal study underscores the value of AI for expanding our pharmaceutical arsenal to include structurally distinct antibacterial drugs.

Another potential role for AI in the realm of infectious diseases is to provide prescription guidance for antibiotics. The use of such decision support systems would be expected to reduce inappropriate prescriptions of antibiotics and antimicrobial resistance. Such systems would apply machine learning techniques or expert systems methods (Figure 1) to data from healthcare databases. Predictions based on a patient's medical information would estimate the probability of the

IF [1] Gram stain is "Gram Positive"
and
[2] Morphology is "Coccus"
and
[3] Conformation is "Chains"
THEN
The organism is possibly "Streptococcus"

Figure 1. An example of an expert system rule pertaining to microbiology. This rule considers three organism-related factors (Gram stain, morphology, and conformation) to produce a conclusion that is probabilistic rather than certain. Example derived from Johnson L, Keravnou ET. Expert systems technology: a guide. Cambridge (MA): Abacus Press; 1985. 
patient having a particular pathogen and provide an early warning regarding the risk of sepsis development [3].

Excessive antibiotic use and the emergence of multi-drug resistant organisms (MDROs) is a major health problem $[4,5]$. Pathogens such as methicillin-resistant Staphylococcus aureus are now common and pose significant health risks. Clinicians are faced with a dilemma when treating sepsis caused by MDROs given the limited choice of effective antibiotics [6], as the indiscriminate use of antibiotics enhances the emergence of MDROs, which in turn burdens healthcare systems with the diagnosis and treatment of critically ill patients. This reality entails a hefty human and financial cost [7].

Antimicrobials work by disrupting bacterial multiplication, often by damaging the cell membrane (Table 1, Figure 2). However, few new antibiotics have been developed in recent decades, and there is a concern that we could eventually face the same problems that our ancestors experienced, with simple infections developing into life-threatening sepsis.

Antimicrobial resistance occurs through two principal mechanisms: mutation and the acquisition of resistance from another organism. In the former case, a mutated bacterium may (for example) produce an enzyme that inactivates a class of antibiotics or develop a mechanism to expel that antimicrobial from the bacterium before it reaches its cellular target. Known mechanisms of acquiring resistance from another organism include transfer of genetic information via conjugation, the acquisition of "naked" free DNA from the environment, or DNA transfer achieved via viral delivery [8].

Researchers have already collaborated on the use of AI in radiology, dermatology, pathology, and ophthalmology to improve care [9]. In addition to diagnosis, AI supports prognosis-related applications, such as predicting sepsis [10],

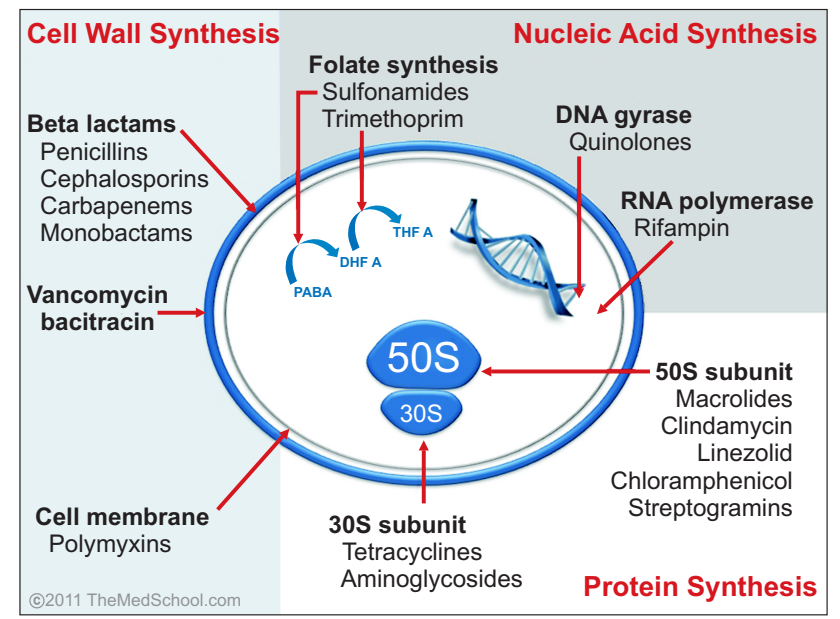

Figure 2. Illustration of some of the known mechanisms of antibiotic action. These include the inhibition of cell wall biosynthesis, inhibition of nucleic acid metabolism and repair, and protein synthesis inhibition, in addition to cell membrane disruption. Adapted from https://commons.wikimedia.org/wiki/File:Antibiotics_Mechanisms_ of_action.png.

Table 1. Various mechanisms of antibiotic action

\begin{tabular}{ll}
\hline \multicolumn{1}{c}{ Mechanism } & Description \\
\hline Enzyme inhibition & $\begin{array}{l}\text { Popular enzyme targets include transpeptidases, transglycosylases, topoisomerases, RNA poly- } \\
\text { merase, and peptidyl transferases. }\end{array}$ \\
$\begin{array}{l}\text { Interference with cell } \\
\text { membrane permeability }\end{array}$ & $\begin{array}{l}\text { Fram-negative bacteria by binding to membrane phospholipids. } \\
\text { Interference with cell }\end{array}$ \\
wall synthesis & The cellular contents of bacteria are surrounded by an inner peptidoglycan cell wall in addition \\
& to an inner plasma membrane. Gram-negative bacteria have an additional outer lipid bilayer. \\
& Antibacterials in this class interfere with cell wall synthesis, damaging the peptidoglycan scaffold \\
Interference with DNA & Dithin the bacterial wall. \\
synthesis & interfere with bacterial topoisomerase II, while fluoroquinolones act similarly. \\
Interference with protein & Protein synthesis is a complex, multi-step process involving many enzymes and requiring con- \\
synthesis & formational alignment. Aminoglycosides are antibiotics that block bacterial protein synthesis, \\
& interfering with the processes in the bacterial ribosome. \\
Interference with the cell & The electrochemical gradient is necessary to produce ATP (a molecule that provides energy for \\
membrane's electroche- & many cellular processes), and disruption of this gradient is the proposed mechanism by which \\
mical gradient & the novel antibiotic halicin works.
\end{tabular}

Information taken from www.sigmaaldrich.com and other online sources. See also Figure 2. 
with alerts generated by an AI model that provides an early warning. Such models predict deterioration and suggest possible pathogens and antibiotic susceptibility [11]. Schinkel et al. [12] reviewed the clinical applications of AI in sepsis and concluded that AI has the potential to prompt physicians when to intervene. Although these models offer a marginal advantage over current tools, data interpretation can be difficult [12]. Giacobbe et al. [13] reviewed applications of AI in the management of multidrug-resistant Gram-negative infections, classifying algorithms into applications such as predicting infection risk, identifying the aetiology, estimating the risk of emerging MDROs, and identifying antibiotic misuse [14].

The development of clinical decision support (CDS) systems remains a daunting challenge, as improving their positive predictive value is critical to improving performance and reducing alert fatigue. However, some studies may overestimate model performance due to poor adaptability and the definition of sepsis. There is also the matter of how alerts affect the provider's actions and prescribing behaviour, as alert and CDS systems need to have a predictive value of over $60 \%$ to avoid alert fatigue [10]; therefore, developers need to understand these factors and their impact on clinical management. Unsurprisingly, evaluations of these systems by their own developers tend to report more favourable outcomes than evaluations conducted by a third party [15].

In conclusion, while medical AI offers promising opportunities to improve outcomes, our focus must be to solve clinical problems and not merely throw technology at patients. If history is kind to us again, in a hundred years, scientists will be looking back at us in the same way we viewed Alexander Fleming's mould discovery.

\section{Conflict of Interest}

No potential conflict of interest relevant to this article was reported.

\section{Acknowledgments}

Zaki Almallah has been awarded a grant from Mubadala Healthcare for a proposed project on AI in antibiotics. No funding for writing this manuscript.

\section{ORCID}

Zaki Almallah (https://orcid.org/0000-0003-0746-7001)

Rania El-Lababidi (https://orcid.org/0000-0002-8707-6627)
Farah Shamout (https://orcid.org/0000-0002-6076-725X)

Daniel John Doyle (https://orcid.org/0000-0003-2861-2992)

\section{References}

1. Stokes JM, Yang K, Swanson K, Jin W, Cubillos-Ruiz A, Donghia NM, et al. A deep learning approach to antibiotic discovery. Cell 2020;181(2):475-83.

2. Corsello SM, Bittker JA, Liu Z, Gould J, McCarren P, Hirschman JE, et al. The Drug Repurposing Hub: a nextgeneration drug library and information resource. Nat Med 2017;23(4):405-8.

3. Colman AM, Krockow EM, Chattoe-Brown E, Tarrant C. Medical prescribing and antibiotic resistance: a gametheoretic analysis of a potentially catastrophic social dilemma. PLoS One 2019;14(4):e0215480.

4. Zilahi G, Artigas A, Martin-Loeches I. What's new in multidrug-resistant pathogens in the ICU? Ann Intensive Care 2016;6(1):96.

5. Su LH, Chen IL, Tang YF, Lee JS, Liu JW. Increased financial burdens and lengths of stay in patients with healthcare-associated infections due to multidrug-resistant bacteria in intensive care units: a propensity-matched case-control study. PLoS One 2020;15(5):e0233265.

6. Ho VP, Kaafarani H, Rattan R, Namias N, Evans H, Zakrison TL. Sepsis 2019: what surgeons need to know. Surg Infect (Larchmt) 2020;21(3):195-204.

7. Arefian H, Heublein S, Scherag A, Brunkhorst FM, Younis MZ, Moerer O, et al. Hospital-related cost of sepsis: a systematic review. J Infect 2017;74(2):107-17.

8. Khan A, Miller WR, Arias CA. Mechanisms of antimicrobial resistance among hospital-associated pathogens. Expert Rev Anti Infect Ther 2018;16(4):269-87.

9. Garcia-Vidal C, Sanjuan G, Puerta-Alcalde P, MorenoGarcia E, Soriano A. Artificial intelligence to support clinical decision-making processes. EBioMedicine 2019; 46:27-9.

10. Downing NL, Rolnick J, Poole SF, Hall E, Wessels AJ, Heidenreich P, et al. Electronic health record-based clinical decision support alert for severe sepsis: a randomised evaluation. BMJ Qual Saf 2019;28(9):762-8.

11. Alam N, Hobbelink EL, van Tienhoven AJ, van de Ven PM, Jansma EP, Nanayakkara PW. The impact of the use of the Early Warning Score (EWS) on patient outcomes: a systematic review. Resuscitation 2014;85(5):587-94.

12. Schinkel M, Paranjape K, Nannan Panday RS, Skyttberg N, Nanayakkara PW. Clinical applications of artificial intelligence in sepsis: a narrative review. Comput Biol 
Med 2019;115:103488.

13. Giacobbe DR, Mora S, Giacomini M, Bassetti M. Machine learning and multidrug-resistant gram-negative bacteria: an interesting combination for current and future research. Antibiotics (Basel) 2020;9(2):54.

14. Beaudoin M, Kabanza F, Nault V, Valiquette L. Evaluation of a machine learning capability for a clinical deci- sion support system to enhance antimicrobial stewardship programs. Artif Intell Med 2016;68:29-36.

15. Roshanov PS, Fernandes N, Wilczynski JM, Hemens BJ, You JJ, Handler SM, et al. Features of effective computerised clinical decision support systems: meta-regression of 162 randomised trials. BMJ 2013;346:f657. 